\title{
ENSINO DA LEITURA DE IMAGEM: EXPRESSÃO SEMÂNTICA E CONTEÚDO SINTÁTICO
}

\section{ENSAIO TEÓRICO}

STUMPF, Katiusa ${ }^{1}$

STUMPF, Katiusa. Ensino da leitura de imagem: Expressão semântica e conteúdo sintático. Revista Científica Multidisciplinar Núcleo do Conhecimento. Ano 05, Ed. 06, Vol. 07, pp. 135-143. Junho de 2020. ISSN: 2448-0959, Link de acesso: https://www.nucleodoconhecimento.com.br/comunicacao/expressaosemantica

\section{RESUMO}

Nesse ensaio é apresentada uma breve discussão sobre o ensino da leitura de imagem. Para isso, é feito um estudo de caso, considerando principalmente as características de expressão e de conteúdo da imagem. Entende-se que a leitura de imagem é imediata e media informação numa relação de alteridade, ou seja, a imagem media a interação do seu autor com o outro, o observador, transmitindo informações e valores. No caso da fotografia, o fotógrafo apresenta um recorte de mundo, sua visão de mundo de acordo com os seus valores. Assim, nesse estudo objetivou-se realizar a leitura de uma imagem publicitária de acordo com sua expressividade semântica e seu conteúdo sintático. Por fim, considera-se de extrema pertinência o ensino da leitura imagética no contexto social atual.

Palavras-chave: Ensino da leitura imagética, leitura de imagem publicitária, expressão semântica, conteúdo sintático.

${ }^{1}$ Mestre em Ciência da Informação - UFSC. 


\section{INTRODUÇÃO: O ENSINO DA INFORMAÇÃO IMAGÉTICA E OS LEITORES DE IMAGEM}

A vida, que vai do poder à crítica do poder, está estruturada em informações, em um vasto universo de informações apresentadas em textos, imagens, multimídias, etc. Grande parte da população não tem acesso a isto ou não sabe como desfrutar das possibilidades existentes. Aliás, de acordo com Maffesoli (2008), ter acesso à informação não é garantia de crítica ou de inclusão informacional e social, mas aumenta a chance de se conhecer as regras do jogo do mundo da decodificação da informação. Esta parcela da sociedade tem muito mais chance de acreditar no que vê e ouve primariamente do que uma pessoa que recebeu instruções para uma competência informacional, que foi em graus variados introduzida no território da crítica e da desconstrução do mundo pela linguagem codificada.

Portanto, pode-se afirmar que para pensar mais as pessoas precisam se envolver com o pensamento de outros que, na prática cotidiana, as levam a rever o que elas mesmas pensam, ou a pensar diferente. Dialogar é construir um pensamento junto com o outro, uma relação de alteridade. É busca de encontro com o outro em nome de ideias e conceitos no intuito de entender mais, de almejar a compreensão.

Neste sentido é possível dizer que todas as pessoas podem se aproximar da ciência apenas pelo esforço de reflexão que constitui uma capacidade de todo ser pensante. Mas na sociedade da informação este esforço não pode acontecer sem mediação. Por isso, é importante que na escola, na universidade, na biblioteca, nas mídias, nas comunidades e instituições em geral, as pessoas sejam motivadas para o pensamento cuidadoso, aquele que cuida da análise e da crítica e luta contra a violência, seja do discurso, seja dos indivíduos, seja das instituições.

Desta forma, segundo Sovik (2003) as pessoas podem ser capacitadas no processo de decodificação informacional para enfrentar o conturbado mundo das informações, das tentativas de manipulações que fazem parte de um processo de políticas nacionais e internacionais provenientes de sucessivos períodos da história. 
Neste contexto destaca-se o poder da imagem como informação que é pouco investigada, pouco trabalhada em termos de alfabetização imagética. Muito embora o mundo esteja repleto de linguagem imagética, existe uma carência de capacitação para interpretação da imagem, que não é uma linguagem universal. A maior parcela da sociedade consegue fazer apenas uma leitura superficial de uma imagem, compreendendo suas características objetivas e superficiais, o que está expresso de forma semântica, mas sem adentrar o seu conteúdo. Necessita-se de uma maior compreensão da imagem e de sua importância não só como meio de comunicação, mas como auxiliar significativo para as tarefas de ensino e pesquisa.

A imagem deixou de ser apenas arte e transformou-se em informação e conhecimento. Expandiu-se por meio de jornais, revistas científicas e de entretenimento, televisão e fotografia. As novas tecnologias computacionais desenvolveram maiores possibilidades de produção e uso de imagens, permitindo uma hipermidiação com outros modos de comunicação.

A imagem apresenta cada dia maior importância como meio de expressão na sociedade, o que provoca um aumento contínuo do patrimônio gráfico por esta gerado. A cada dia que passa os arquivos fotográficos dos jornais são maiores. O mesmo sucede em empresas e instituições que são obrigadas a organizar seus acervos. Por outro lado, o consumo de imagens tornou-se um fato diário na vida das pessoas, a existência de bancos de imagens, por exemplo, tornou-se habitual; assim como a de revistas especializadas em fotografia. A publicidade com imagens faz parte do contexto social atual. E os periódicos apresentam parte de suas notícias em fotografias. Na sociedade atual a linguagem gráfica ocupa cada vez maior espaço.

As pessoas se encontram familiarizadas com as operações relacionadas com o texto escrito, mas há ainda muitas coisas a serem observadas na leitura das imagens, sejam elas uma pintura, um filme, uma fotografia, uma charge, etc.

O primeiro aspecto que destacam os estudiosos da leitura das imagens é o caráter polissêmico desse recurso, ou seja, a multiplicidade de significados existentes nessa 
fonte de informações. Como no documento escrito, as imagens requerem análise, estabelecimento de comparações, semelhanças, coincidências, repetições.

Neste sentido Manguel (2001) defende a ideia de que os não-especialistas têm o direito de ler imagens como quem lê um texto. Segundo o autor as imagens são como histórias à espera de um narrador. E o espectador deve descobrir as histórias explícitas ou implícitas. No entanto, nem sempre essas imagens são de fácil leitura, tanto que, para tentar fazer a leitura é necessário saber ver, interpretar.

Sabe-se, contudo, que esse trabalho de interpretação da imagem, tanto quanto na compreensão de textos verbais, vai pressupor também a relação com o cultural e o histórico, como explica sabiamente Frei Betto, em Betto e Gleiser (2011), ao dizer que não existe uma leitura neutra, pois entre os olhos e o texto existem óculos que são incutidos pela cultura. Bem como Matins (2007), ao propor que a imagem também é um produto social e histórico, pois se traduzem em noções, crenças e valores, além de registrarem informações culturais e práticas de períodos distintos. Trata-se de características de conteúdo sintático.

Sendo assim, não se pode trabalhar com a imagem como se ela fosse transparente e sim entendê-la como linguagem, produzida dentro de um contexto sócio-histórico e cultural. Entendendo ainda, segundo Manguel (2001), que a linguagem visual ao ser interpretada também permite a projeção de outras imagens, que podem estar relacionadas a outros contextos simbólicos do leitor.

Por isso pode-se inferir que existe a necessidade de proporcionar aos cidadãos, sem exclusão, o acesso e o contato direto à informação imagética, para que estes tenham a oportunidade de decifrar seus códigos de acordo com seu referencial subjetivo, mas também com clareza, tendo conhecimento das possíveis estratégias manipuladoras existentes por trás de tantas informações. O ensino da leitura de imagens é cada vez mais urgente no contexto atual e os leitores de imagem precisam ser instruídos da mesma forma que os leitores de texto, de forma gradual e reflexiva, em um verdadeiro processo educativo. 
Compreendendo essa discussão, é apresentada a leitura de uma imagem publicitária, conforme o tópico seguinte.

\section{LEITURA DE UMA IMAGEM PUBLICITÁRIA}

A imagem selecionada para esse estudo não teve critérios específicos de seleção, foi escolhida de forma aleatória, decorrente de navegação na Internet, quando se buscava por imagens através do Google.

FIGURA 1. Imagem publicitária, da Coca Cola, em Festival brasileiro de 2008.

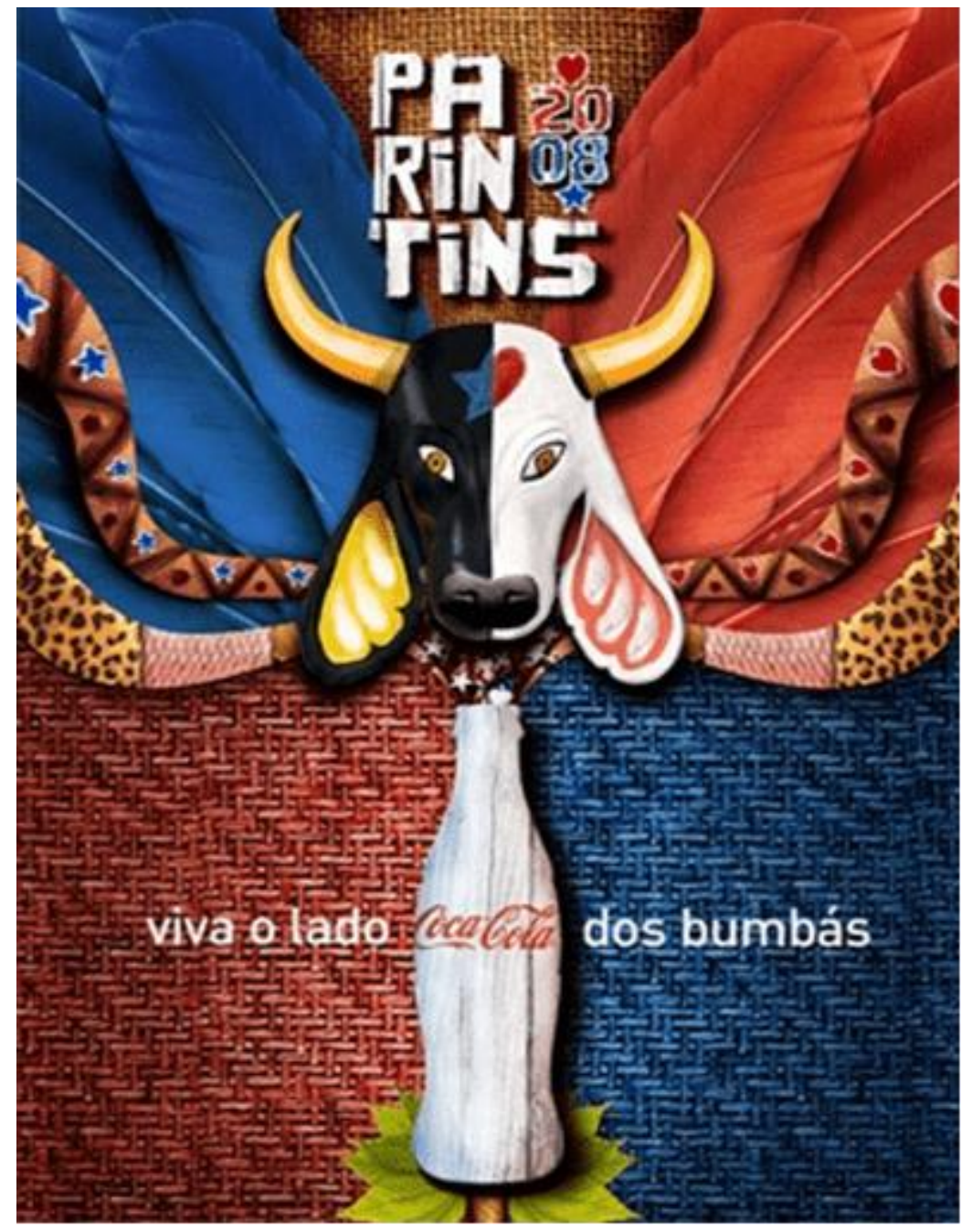

Fonte: Internet: http://www.pdvnews.com.br/coca-cola-azul 
A imagem traz, como centro de atenção a cabeça de um boi, sendo que a metade esquerda da cabeça é de cor preta, trazendo na altura da testa o desenho de parte de uma estrela azul. A metade direita da cabeça do boi, de cor branca, traz, também na altura da testa, parte de um coração vermelho. Abaixo da cabeça do boi, a imagem aparece dividida entre as cores azul à direita e vermelha à esquerda, em que a textura apresentada aparenta um tipo de trama feita com palha ou algum outro tecido ou material rústico. Exatamente no meio da divisão entre as cores, destaca-se uma garrafa de cor branca com a logo marca da Coca Cola, que identifica a garrafa de refrigerante. A frase "viva o lado coca-cola dos bumbás" está centralmente localizada conforme a logo marca do refrigerante. Logo abaixo da garrafa aparece um pequeno arranjo de folhas verdes, como se sustentassem a garrafa. A frase em questão faz referência ao slogan "viva o lado coca-cola da vida", que, por sua vez, faz analogia ao ditado popular "viva o lado bom da vida". Acima da cabeça do boi estão dois arranjos de penas, que lembram um cocar indígena. A metade esquerda do arranjo de penas é da cor azul e a metade direita, da cor vermelha. De dentro da garrafa saem duas linhas que se direcionam para a esquerda e duas que se direcionam para a direita, acompanhando o movimento das penas. As linhas têm desenhos que lembram a pele de animais, sendo as linhas da direita, uma remetendo aos desenhos da pele de onça e outra remetendo aos desenhos da pele de cobra com pequenas estrelas azuis. Nas linhas do lado esquerdo, uma remete aos desenhos da pele de onça e outra remete aos desenhos da pele de cobra com pequenos corações vermelhos.

Acima da cabeça do boi, no espaço central superior da imagem, entre os arranjos de pena, aparece o nome de Parintins e o ano 2008, identificando que a imagem publicitária se refere ao festival do ano de 2008. O número que identifica o ano também aparece com a cor vermelha (números "2" e "0") com o desenho de um coração acima dos números, e azul (números "0" e "8") com o desenho de uma estrela abaixo dos números. Onde aparece escrito o nome de Parintins e o ano 2008, a cor de fundo é uma cor neutra, um marrom claro lembrando cor de palha, com uma textura similar a de uma trama de palha. 
A cabeça do boi colocada bem no centro da imagem e com os símbolos na altura da testa remete imediatamente ao Festival Folclórico de Parintins, pelo menos àqueles que têm algum conhecimento da cultura do festival.

O Festival Folclórico de Parintins é um evento popular brasileiro que acontece anualmente, geralmente na última semana de junho, na cidade de Parintins no Estado do Amazonas. No Festival são realizadas apresentações em espaço aberto (no Bumbódromo) onde competem duas agremiações: o Boi Garantido e o Boi Caprichoso, que fazem parte da lenda do "boi-bumbá". Durante três dias consecutivos, acontecem os desfiles de cada boi sempre com a exposição, por meio de músicas e alegorias, de temas relacionados à cultura indígena, lendas e costumes dos ribeirinhos. Cada boi tem um símbolo e uma cor característica, sendo o Boi Garantido, a cor vermelha e um coração como símbolo, e o Boi Caprichoso, a cor azul e uma estrela como símbolo. $O$ festival atualmente tem grande impacto no turismo da região e é um dos maiores festivais folclóricos do Brasil. O folclore do boi-bumbá é bastante forte na cultura dos moradores da região, onde, nos dias dos festivais, as residências e estabelecimentos comerciais adotam as cores do seu boi favorito em decorações, mobiliários e outros. A Coca-cola é um dos principais patrocinadores do evento e, como a competição entre os bois é muito forte, a empresa adotou um forte apelo comercial introduzindo a distribuição do refrigerante em latas de cor vermelha e de cor azul no período que antecede e até o fim do festival, a fim de "garantir" consumidores de ambos os bois. Como marketing turístico, o refrigerante se destaca pois é mundialmente reconhecido pela lata vermelha, mas oferece o diferencial da lata azul somente no Festival de Parintins.

A cor branca na garrafa centralizada e exatamente abaixo da cabeça do boi remete à uma neutralidade entre os Bois do festival, como se deixasse a critério do consumidor estabelecer que cor a garrafa deve ter, conforme o Boi de sua preferência. A frase "viva o lado coca-cola dos bumbas" é o slogan adotado pela Coca-cola e é utilizado em diversas propagandas do refrigerante, sempre adaptado a determinada região, data comemorativa, evento, etc. (por exemplo: "viva o lado coca-cola do futebol"). 
Todos os motivos, cores e texturas sugeridas pela imagem remetem à cultura local, especialmente indígena, da região norte do Brasil (palha, trama artesanal, penas, cocar, boi, símbolos, folhas), demonstrando um forte apelo comercial por meio da identificação do produto com os costumes da região.

\section{CONSIDERAÇÕES FINAIS}

No contexto da era da informação, considera-se desejável, do ponto de vista de crescimento da sociedade, que haja cada vez mais a intervenção de políticas governamentais públicas, de profissionais capacitados e engajados politicamente na luta contra as desigualdades informacionais e sociais.

O profissional que atua na educação é extremamente importante nesse contexto porque é o mediador da informação. Cabe a este profissional, portanto, promover o acesso à informação para todos os cidadãos de forma igualitária, o que pode ser alcançado por meio de um envolvimento maior destes profissionais no desenvolvimento de políticas para inclusão informacional e social.

A capacitação para decodificação da informação imagética pode acontecer por meio da interdisciplinaridade, ou seja, a coparticipação de profissionais da comunicação, como o fotógrafo, por exemplo, e educadores. É preciso ter em mente que a sociedade evolui e os profissionais que a servem devem evoluir também.

O conhecimento do poder da imagem como meio de representação social é de grande importância na alfabetização imagética de todo e qualquer cidadão que deseje escapar dos processos de manipulação midiática, dos abusos publicitários de apelo ao consumo excessivo, do sensacionalismo e da violência etc.

Nesse sentido o estudo de caso apresentado revela quanta informação pode estar presente em uma imagem, podendo ser ou não identificada. Expressões semânticas logo podem ser observadas e descritas por seu observador, conforme a primeira parte da leitura. Por outro lado, o conteúdo sintático só é identificado com uma leitura mais apurada que envolve a relação das características objetivas da imagem com o 
referencial que cada pessoa possui. Nesse caso, o conhecimento do Festival e do poder publicitário da Coca-cola no contexto da sociedade do consumo e da região onde o evento ocorreu.

\section{REFERÊNCIAS}

ASSOCIAÇÃO BRASILEIRA DE NORMAS TÉCNICAS. NBR 14 724: informação e documentação: trabalhos acadêmicos: apresentação. Rio de Janeiro, 2005.

BETTO, Frei; GLEISER, Marcelo. Conversa sobre fé e ciência. Rio de Janeiro: Agir, 2011.

MAFFESOLI, Michel. A comunicação sem fim. In: MARTINS, Francisco Menezes; SILVA, Juremir Machado da (Org.). A genealogia do virtual. 2008, p.20-32.

MANGUEL, Alberto. Lendo imagens: uma história de amor e ódio. São Paulo: Companhia das Letras, 2001.

MARTINS, Raimundo. Educar com imagens: múltiplos tempos e interpretação. BOLETIM ARTE NA ESCOLA, n. 45, Abr. 2007.

PARINTINS. Disponível em: <http://www.parintins.com/>. Acesso em: 10 nov. 2011.

PDV NEWS. Disponível em: <http://www.pdvnews.com.br/coca-cola-azul/>. Acesso em: 10 nov. 2011.

PROPMARK.

em:

$<$ http://www.propmark.com.br/publique/cgi/cgilua.exe/sys/start.htm?infoid=45717\&sid $=3>$ Acesso em: 12 nov. 2011.

SOVIK, Levi. (Org.). Reflexões sobre o modelo de codificação/decodificação: uma entrevista com Stuart Hall. In: HALL, Stuart. Da diáspora: identidades e mediações culturais. Belo Horizonte: Editora UFMG; Brasília: Representação da UNESCO no Brasil, 2003. 
Enviado: Fevereiro, 2020.

Aprovado: Junho, 2020. 